and, as the literature of protein chemistry shows, has been used to good effect. The difficulties have been widely enough discussed and publicized. If Professor Kenner feels that the practical advantages of the solid-phase method are all a great delusion, then I am sure no one will be listened to with greater interest.

\section{Economics and Ecology}

SIR,-Of recent years it has seemed that the needs of our environment, as seen by ecologists, and the needs of process technologists, epitomized by the laws of economics, were irrevocably opposed. We need to seek any means for moderating this conflict. One of the contentious issues is the limited term of years for which patents run. It is in the early years that a manufacturer may make most profit from a valuable patented process. Moreover, the operative term of years runs from the sealing date. The manufacturer is unlikely willingly to accept the advice of an ecologist that several years may be needed to evaluate whether by-products from working a patent will or will not harm the environment.

After three months or so an application for a patent may be granted. If, then, the patentee does not arrange for the use of the process which is the subject of the patent the monopoly rights may be lost. No provision is made for delay while ecological studies assess whether working the patent may damage the environment. Notoriously ecologists find it difficult to give straight answers to straight questions posed by technologists, but the more the time that is available the easier it is to arrive at a straightforward answer. Since three years is probably a minimum time to obtain sufficient information to attempt reasonably confident judgments, I suggest as a compromise that the needs of environmental protection would be furthered if the operational date for a patent covering a chemical process could be deferred for, say, three years after the sealing or granting date.

The decision as to whether such ecological evaluation is necessary would be made by Patent Office examiners, acting on the advice of environmental ecologists on the staff of governmental laboratories such as those of the Ministry of Agriculture, Fisheries and Food or the Water Pollution Research Laboratory.

The necessary assessment of the environmental consequences of newly patented processes could be referred to an ecological laboratory which might well develop under the wing of the Government Chemist but be largely financed by fees from firms soliciting patent protection for new processes. This laboratory would assess the environmental hazards inherent in new processes submitted for Letters Patent. Its reports could include statements of the kinds of treatment needed to render harmful effluents harmless and would be submitted back to the Patent Office whose examiners would have acquired the experience to check, evaluate and implement the ecological findings.

A process patent, tentatively sealed under the present patent laws, would become operational only on the date of approval by the ecological examiners and with any operational restrictions which they might think fit to impose.

During the period of evaluation the manufacturer would be protected from pirating of his process and would then have the full term of years in which to exploit his patent. The environment would be protected much more than it now is. Economics and ecology would learn to live together.

Any country which unilaterally adopted such a development of Patent Law would place its manufacturers at a disadvantage compared with manufacturers which did not have to work within such a law. Clearly international agreement would be needed before any country could enforce such a law.

There may be circumstances in which a manufacturer, introducing a new process which he knew could provide a hazard to the environment, would circumvent the law by the simple expedient of not applying for patent protection. To meet this situation the law would need to contain the provision that a new emission to the environment of any substance or form of energy is presumed to be hazardous to the environment until it has been proved not to be so to the satisfaction of the appropriate Inspecting Officer or Patent Examiner.

To sum up, wise international development of the Patent Laws could provide effective control of adverse effects of new technological emissions upon the environment.

$$
\begin{aligned}
& \text { Yours faithfully, } \\
& \text { L. H. N. CoOPER }
\end{aligned}
$$

The Laboratory,

Citadel Hill,

Plymouth

\section{Insect Taxonomy}

SIR,-It is not only in Britain that insect taxonomy is regrettably so neglected (Nature, 238, 475; 1972). The same situation obtains in many other countries. I am told by colleagues abroad, and am a witness to the problem myself, that the always notoriously limited financial and moral support for this field of enquiry is in fact decreasing yearly. In this context, the following points may prove of some interest.

(1) Registration of existing species, and arranging them into a system which would make possible reasonable orientation in an immense insect diversity, species identification, and suitable classification of any kind of information on insects - these are the primary goals of insect taxonomists. But because of the imbalance between the extent of the group (some 1,000,000 species recognized and several times as many still unknown) and the limited number of taxonomists on a world-wide scale, the field still suffers from substantial lacunae even in the most basic descriptive data.

(2) A vast amount of work has been done and is still being done by amateur entomologists. The result is that the layman cannot always understand how severely insect taxonomy is understaffed. Moreover, factors such as rising expenses of all kinds and the growing necessity for entomologists to gain a broader biological background logically render it difficult for amateurs to keep in step with the professionals.

(3) Insect taxonomists play a double role in society: they do research and they provide identification services. The importance of precise identification for applied biology, as well as for the standardization of biological material for further study, is generally recognized; but few people are aware how very frequently such services are required. Usually, reliable identification can only be undertaken by research taxonomists actively working in the pertinent groups of insects. Yet the world-wide shortage of experienced specialists frequently results in these services being provided by less qualified persons, with a consequent high percentage of misidentifications or nomenclatorial inaccuracies. Chronic scarcity of identification manuals, catalogues, cumulative faunal lists, and similar reference works is another consequence of this state of affairs.

(4) It is still possible to achieve serious and often outstanding scientific advances in insect taxonomy by the use of simple methods and with minimum expense. It is absurd to consider this a shortcoming or a reason for reduced monetary support; it would be equally ludicrous to look down on insect taxonomy as an obsolete science where "everything has already been done" simply because it has been intensively pursued for more than two centuries. It cannot be stressed too emphatically that the taxonomic field necessitates not only extensive development of basic, descriptive and registratory work, but also substantial advances at the higher, synthetic and causal levels. This requires an interdisciplinary approach and consequently the use of varied 